\section{First record of the catfish Gagata dolichonema He, 1996 (Siluriformes: Sisoridae) from India}

\section{W. Vishwanath ${ }^{1} \&$ A. Darshan ${ }^{2}$}

\author{
1, 2 Department of Life Sciences, Manipur University, Canchipur, \\ Manipur 795003, India \\ Email: ${ }^{1}$ wvnath@gmail.com
}

Bleeker (1856) erected the genus Gagata to accommodate Pimelodus gagata (now Gagata gagata). de Pinna (1996) divided the family Sisoridae Bleeker into Subfamilies Sisorinae and Glyptosterninae. Under subfamily Sisorinae and tribe Sisorini he proposed subtribe Nangrina and accommodated genus Gagata. Genus Gagata is diagnosed in having compressed head; eyes on side of head; depressed snout; small conical teeth in lower jaw; branchiostegal membranes broadly fused to isthmus; no serrations on anterior margin of pectoral spine; no well developed maxillary barbel membrane; outer and inner mental barbels close together with their origins nearly parallel, in a transverse line; short nasal and maxillary barbels; palatal teeth absent (Thomson \& Page 2006).

Hamilton (1822) described Gagata cenia from rivers in the northern part of Bengal. He (1996) described G. dolichonema from Yunnan, China and Roberts \& Ferraris (1998) described G. gasawyuh from Tenasserim River, Myanmar. Ferraris (2007) considers G. gasawyuh a junior synonym of G. dolichonema. The species differs from $G$. cenia in having a continuous blue black lunate mark on caudal fin, the tips pointing caudad (vs. two separate broad blue black bars in the middle of the two limbs of caudal fin); saddles on the body extend well below lateral line (vs. terminate at the level of lateral line).

Manipur state, in the northeastern region of India, is drained by two river systems, viz., Brahmaputra and Chindwin. A series of collections made from the headwaters of Chindwin in the state included some Gagata which are G. dolichonema. This paper records the species from India and gives a brief description of the materials.

Date of publication (online): 26 November 2009

Date of publication (print): 26 November 2009

ISSN 0974-7907 (online) | 0974-7893 (print)

Editor: M. Arunachalam

\section{Manuscript details:}

Ms \# 01840

Received 17 August 2007

Final received 04 September 2008

Finally accepted 30 October 2009

Citation: Vishwanath, W. \& A. Darshan (2009). First record of the catfish Gagata dolichonema He, 1996 (Siluriformes: Sisoridae) in India. Journal of Threatened Taxa 1(11): 578-580.

Copyright: (C) W. Vishwanath \& A. Darshan 2009. Creative Commons Attribution 3.0 Unported License. JoTT allows unrestricted use of this article in any medium for non-profit purposes, reproduction and distribution by providing adequate credit to the authors and the source of publication.

Acknowledgments: The authors are grateful to Ministry of Environment \& Forests (Project No. 14/11/2006/ERS/RE) for financial assistance.

OPEN AGGESS | FREE DOWNLOAD

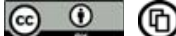

\section{Materials and Methods}

Materials examined are deposited in MUMF. Measurement was made with dial calipers to the nearest $0.1 \mathrm{~mm}$. Body proportions are expressed in percentages of Standard length (SL) and Head length (HL). Numbers in parentheses indicate number of specimens examined for a particular count. Counts and measurements follow $\mathrm{Ng} \&$ Kottelat (1998). Gill raker counts follow Roberts \& Ferraris (1998) and vertebral count, Roberts (1983). For osteological studies, clearing and staining techniques follow Hollister (1934).

\section{Gagata dolichonema He, 1996}

(Image 1)

Gagata cenia Hora, 1921: 182 (Imphal River and Amambi stream, Chindwin drainage, Manipur).

Gagata cenia Arunkumar \& Tombi, 1997: 131 (listed from Chindwin dranaige, Manipur).

Gagata cenia Vishwanath et al. 1998: 323 (listed from Lokchao River, Chindwin drainage, Manipur).

Gagata dolichonema He, 1996: 380 (type locality: Daojieba of Baoshan County, Yunnan, China)

Gagata gasawyuh Roberts and Ferraris, 1998: 325, fig. 6 and 7 (type locality: Tenasserim River mainstream upstream from Kita or Htee-tah, Myanmar)

Gagata dolichonema, Ferraris, 2007: 628 pp (synonymy)

Materials Examined: 25.xi.1999, MUMF 7055, 3 exs (males), 88.5-100.2 mm SL; 7056, 2 exs. (females), 94.3-116.2 mm SL, Lokchao River, Chandel District, Manipur, India, coll. L. Sakuntala Devi; 23.i.1999, MUMF 9001-9003, 3 exs. (females), 86.1-94.9mm SL, Ithai River, Manipur, India, coll. L. Juliana.

Distribution: Irrawaddy, Salween and Tenasserim basins of Myanmar. Lokchao and Ithai Rivers (Chindwin Basin) Manipur, India.

Diagnosis: The species can be distinguished from other species of Gagata in having five saddles oblique, extending downward and backward; one on head crossing eye, extending to below lower margin of orbit; second at nape across occipital process extending to the pectoral fin base, third at the posterior half of dorsal fin base crossing the lateral line but not reaching pelvic fin, forth at the anterior extent of adipose fin extending obliquely towards anal fin base but not reaching anal fin and another fifth at the base of caudal fin extending ventrally to below lateral line. Caudal fin with a dark grey continuous subterminal lunate mark.

Description: Morphometric data are given in Table 1. Body elongated and slender. Head and body compressed, becoming more compressed posteriorly. Snout bluntly rounded. Median longitudinal groove on head extending from the level of the posterior rim of anterior nostril to the base of occipital process. Occipital process long narrow but not reaching basal bone of dorsal fin. Eyes lateral, covered with thin skin, no free orbital margin. Mouth small, inferior. Oral opening transverse, lies ventral to nares. Upper jaw and palate edentulous. Lower jaw with single row of conical teeth interrupted at the symphysis. Gill opening wide. Gill rakers: $3+7=10(1)$ or $3+8=11$ (2) on the first branchial arch.

Abbreviation: MUMF - Manipur University Museum of Fishes; FDT - flexible distal tip of second dorsal spine; DS2 - second dorsal spine. 


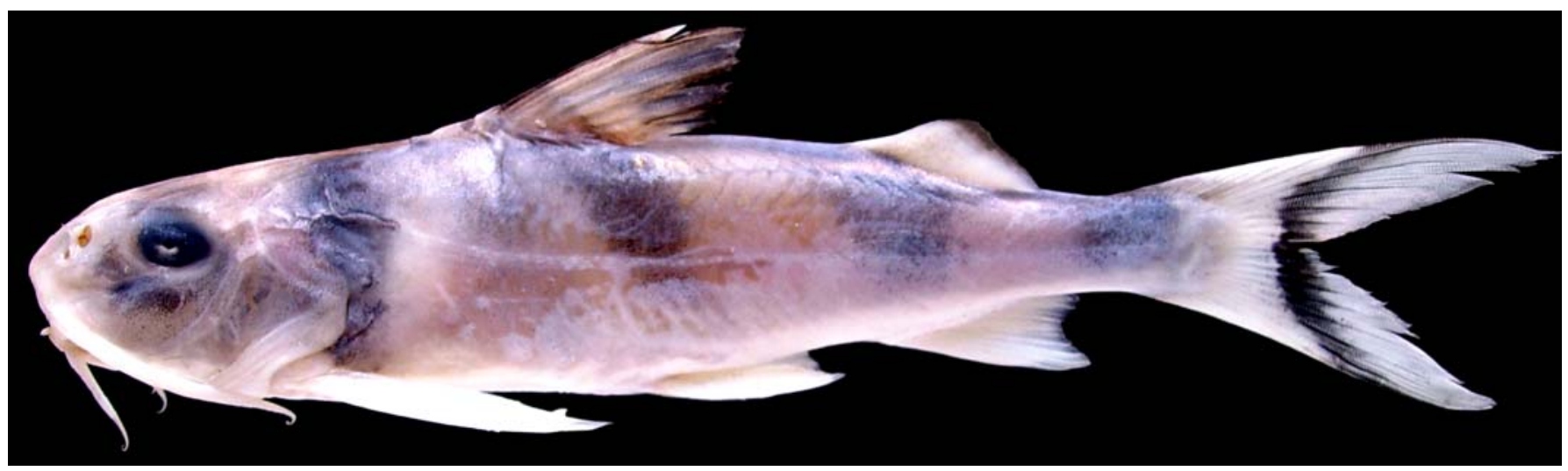

Image 1. General appearance of Gagata dolichonema He, 1996

Barbels four pairs. Maxillary barbel reaching pectoral fin origin or slightly beyond. Nasal barbels minute and its fleshy flap base divide anterior and posterior nares. Mental barbels originate in transverse row and lie just posterior to lower jaw. Outer mandibular barbel reached opercular margin and inner mandibular barbels shorter than the inner.

Dorsal fin with spinelet (first dorsal spine), spine (second dorsal spine) and six branch rays. Second dorsal spine is laterally compressed, smooth on both the posterior and anterior edge, distally flexible. Anterior margin of spine dark and distal half of dorsal fin with broad marginal band. Pectoral fin with a spine and eight-ten branch rays. Anal fin with four or five simple rays and eleven or twelve branch rays. Posterior rays shorter and its distal tip grayish. Fin margin slightly concave. Pelvic fin with one simple and five branch rays. Caudal fin deeply fork with $i, 7,8$,i. principle rays.

Sexual dimorphism: Mature individuals are sexually dimorphic. Males differ from female in having flexible distal tip of second dorsal spine (Fig. 1a) extending well beyond the level of first branched ray vs. extending upto the level of the first branched ray (Fig. 1b); longer genital papilla, posteriorly elongated and its opening is formed at its distal tip (Fig. 2a) vs. shorter genital papilla and its opening is formed at its anteroventral portion (Fig. 2b).

Osteological Character: Branchiostegal rays 7 . Ribs: 8 (1) in numbers. Vertebrae: 22 abdominal +17 caudal $=40(1)$. First fully developed haemal canal and ribs appear on $7^{\text {th }}$ vertebra. This $7^{\text {th }}$ vertebra being the first freely movable vertebra. Caudal plate: parhypural and fused hypural 1 and 2 $\left(\mathrm{H}_{1+2}\right)$ on the lower lobe and fused hypural 3 and $4\left(\mathrm{H}_{3+4}\right)$ and hypural $5\left(\mathrm{H}_{5}\right)$ on upper lobe. Proximal portion of parhypural fused partially with the base of $\mathrm{H}_{1+2}$. One roughly straight, distally taper epural lies above the short neural spine of the last half centrum. Second ural centrum well developed at the base of fused $\mathrm{H}_{3+4}$. Hypuropophysis and secondary hypuropophysis fused. Procurrent rays: 8 segmented +9 unsegmented $=17(1)$ rays on each lobes.

\section{Discussion}

Gagata gasawyuh differs from other known species of Gagata in having five saddles over the dorsum of head and body, and blue black lunate mark at the middle of caudal fin. Diagnostic characters of the species in the present study fit the original description of G. gasawyuh. Some specimens have indistinct saddle at the dorsal fin origin which extends well below the lateral line. Similar cases were reported by Roberts \& Ferraris (1998). However, in contrast to the range of teeth in lower jaw (2-5) they reported, the present alizarin stained specimens show a single row of 16-18 teeth (8-9 each side). The conical teeth row is interrupted at symphysis.

The present work also reports the sexual dimorphism of the species. Tilak (1970) also reported filamentous extension of the dorsal fin spine in males of G. sexualis. There is no report of filamentous extension of dorsal fin spine in $G$. dolichonema He of Yunnan, China as a character of sexual dimorphism.

Hamilton (1822) described Gagata cenia from rivers in the northern part of Bengal. Hora (1921) reported the occurrence of Gagata cenia (Hamilton) from Imphal River and Amambi stream streams, Chindwin drainage, Manipur. Vishwanath \& Tombi (1985), Arunkumar \& Tombi (1997) and Vishwanath et al. (1998) also reported the occurrence of the species from the same basin. Menon (1954) also included the species in his list of fishes from Manipur.

Roberts \& Ferraris (1998), however, reported Gagata cenia to be distributed in the Indus, Ganga and Mahanadi river systems. There are materials collected from Barak River in Manipur (Brahmaputra drainage) which are referable to G. cenia. However, with the description of G. gasawyuh, the records of $G$. cenia from Chindwin basin may be treated as misidentifications and may be replaced by G. gasawyuh. The species is recorded here for the first time from India.

\section{References}

Arunkumar, L. \& H.T. Singh (1997). On a collection of fishes from the head water of Yu-River System with four new records in Manipur. Journal of the Freshwater Biology 9(3-4): 126-133.

Bleeker, P. (1858). De visschen van den Indischen Archipel. Beschreven en toegelicht. Siluri. Acta Societatia Scientiarum Indo-Neerlandicae 4: ixii $+1-370$. [Also published as a separate: Ichthyologiae Archipelagi Indici Prodromus 1: Siluri. Lange and Co., Batavia. i-xii + 1-370.]

de Pinna, M.C.C. (1996). A phylogenetic analysis of the Asian catfish families Sisoridae, Akysidae, and Amblycipitidae, with a hypothesis on the Relationships of the Neotropical Aspredinidae (Teleostei: Ostariophysi). Fieldiana Zoology (New series) 84: 1-83.

Ferraris, C.J. Jr. (2007). Checklist of catfishes, recent and fossil (Osteichthyes: Siluriformes), and catalog of siluriform primary types. Zootaxa 1418: 1-628 pp.

Hamilton, F.B. (1822). An Account of The Fishes Found in The River Ganges and Its Branches. Edinburgh \& London. Fishes Ganges: i-vii + 1-405, Pls. 1-39. 
Table 1. Morphometric data of Gagata dolichonema He, 1996 (in \% of SL and HL)

\begin{tabular}{llll}
\hline \multicolumn{4}{c}{ Gagata dolichonema (MUMF 7055, 7056 and 9001-9003) } \\
\hline Characters in \% of SL & Mean & Range & S.D. \\
Head length & 24.7 & $23.0-27.4$ & 1.8 \\
Head width & 14.1 & $12.5-15.4$ & 1.1 \\
Head depth & 19.7 & $18.1-20.8$ & 1.0 \\
Predorsal distance & 37.9 & $36.1-39.8$ & 1.3 \\
Preanal length & 72.5 & $72.0-73.2$ & 0.5 \\
Prepelvic length & 51.0 & $49.9-52.6$ & 1.1 \\
Prepectoral length & 21.8 & $19.7-23.9$ & 1.5 \\
Body depth at anus & 18.4 & $17.3-19.1$ & 0.7 \\
Caudal peduncle length & 14.8 & $13.9-15.6$ & 0.6 \\
Caudal peduncle depth & 7.8 & $7.3-8.0$ & 0.3 \\
Pectoral fin length & 23.9 & $23.1-26.1$ & 1.2 \\
Pectoral spine length & 20.1 & $18.5-21.3$ & 1.1 \\
Dorsal fin base length & 13.1 & $13.0-13.9$ & 0.7 \\
Dorsal spine length & 17.1 & $16.2-17.8$ & 0.7 \\
Pelvic fin length & 15.2 & $14.1-16.0$ & 0.7 \\
Anal fin base length & 14.4 & $14.1-15.3$ & 0.5 \\
Caudal fin length & 29.1 & $28.5-30.1$ & 0.6 \\
Adipose fin base length & 13.7 & $13.0-14.4$ & 0.6 \\
Dorsal to adipose distance & 22.4 & $20.8-24.8$ & 1.7 \\
In \% of HL. & & & \\
Snout length & 38.2 & $36.9-40.1$ & 1.2 \\
Interorbital distance & 24.4 & $22.1-27.5$ & 2.0 \\
Eye diameter & 30.4 & $27.5-32.6$ & 2.1 \\
Maxillary barbel length & 86.3 & $76.8-94.5$ & 7.2 \\
Inner mandibular barbel length & 34.2 & $32.4-36.9$ & 1.5 \\
Outer mandibular barbel length & 42.9 & $40.7-44.1$ & 1.6 \\
\hline
\end{tabular}

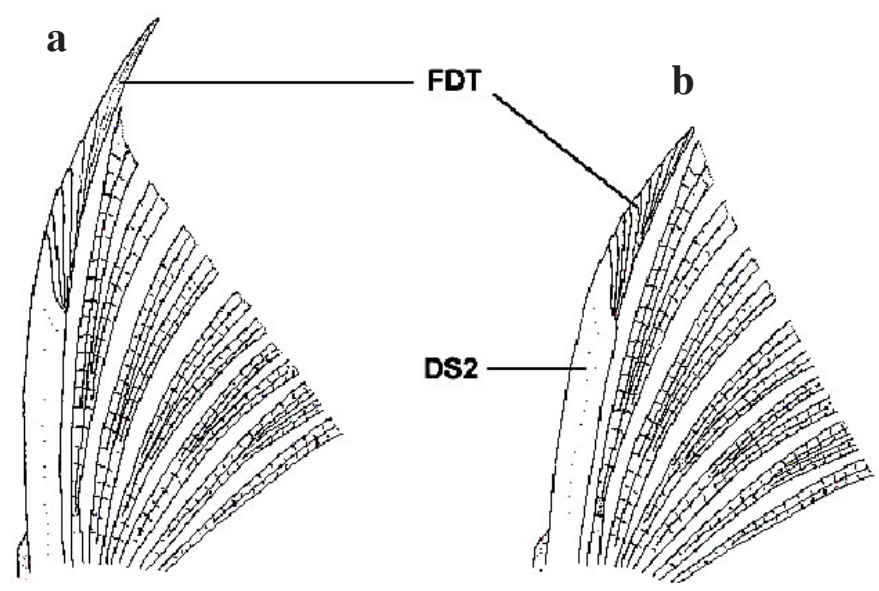

Figure 1. Lateral view of dorsal fin of G. dolichonema He, 1996. a - male; b - female

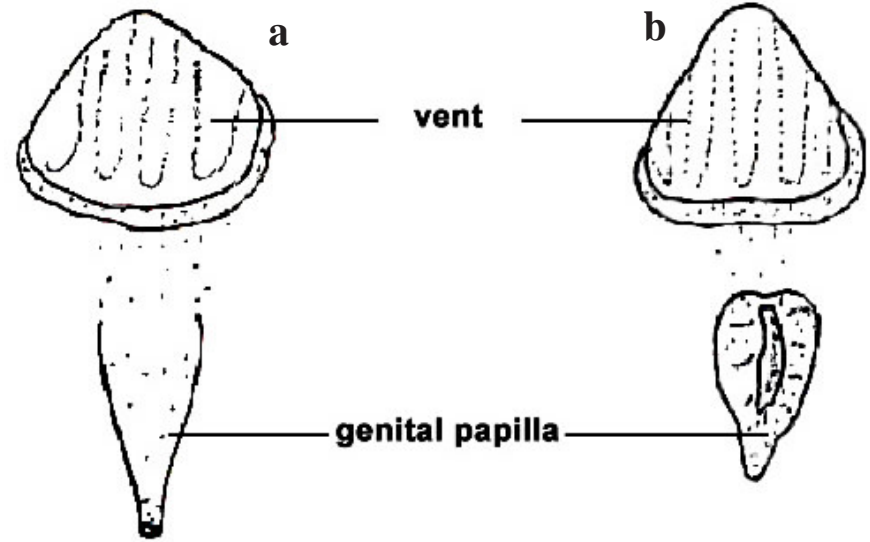

Figure 2. Schematic illustration of the ventral view of external genitalia of G. dolichonema He, 1996. a - male; b female

He, S.P. (1996). A new species of the genus Gagata (Pisces: Sisoridae). Acta Zootaxonomica Sinica 21(3): 380-382.

Hora, S.L. (1921). Fish and fishes of Manipur with some observations on those of Naga Hills. Records of the Indian Museum 22: 166-214.

Hollister, G. (1934). Clearing and dying fishes for bone study. Zoologica 12: 89-101.

Menon, A.G.K. (1954). Further observations on the fish-fauna of the Manipur state. Records of the Indian Museum 52(1): 21-26.

$\mathbf{N g}$, H.H. \& M. Kottelat (1998). Hyalobagrus, a new genus of miniature bagrid catfish from Southeast Asia (Teleostei: Siluriformes). Ichthyological Exploration of Freshwaters 9: 335-346.

Roberts, T.R. (1983). Revision of the south and south-east Asian sisorid catfish genus Bagarius with description of a new species from the Mekong. Copeia 2: 435-445.

Roberts, T. R. \& C.J. Ferraris (1998). Review of south Asian sisorid catfish genera Gagata and Nangara, with description of new genus and five new species. Proceedings of the California academy of sciences $50(14): 315-345$.

Tilak, R. (1970). A new sisorid catfish of the genus Gagata Bleeker from India. Zoologische Mededelingen (Leiden) 44(14): 207-215.

Thomson, A.W. \& L.M. Page (2006). Genera of the Asian Catfish Families Sisoridae and Erethistidae (Teleostei: Siluriformes). Zootaxa 1345: 1-96.

Vishwanath, W. \& Tombi (1985). On the collection of fishes from Tengnoupal District of Manipur with some new records. International Journal of Academic Ichthyology (Proc. v. AISI) 6: 85-90.

Vishwanath, W., W. Manojkumar, L. Kosygin \& K. Selim (1998). Biodiversity of freshwater fishes of Manipur, India. Italian Journal of Zoology (Modena) 65: Suppl: 321-324. 